Handep Jurnal Sejarah dan Budaya Vol. 3, No. 1, Desember 2019, hlm. 33-54

\title{
PEMIKIRAN MODERNISASI \\ EKONOMI BUMIPUTRA DALAM SURAT KABAR \\ BOEDI OETOMO DAN SOEARA MOEHAMMADIJAH \\ DI HINDIA BELANDA (1920-1928)
}

\author{
THE THOUGHT OF ECONOMIC MODERNIZATION \\ OF BUMIPUTRA IN BOEDI OETOMO \\ $A N D$ SOEARA MOEHAMMADIJAH \\ IN THE DUTCH EAST INDIES (1920-1928)
}

\author{
Rechardus Deaz Prabowo \\ SMA Kanisius, Jakarta \\ Jln. Menteng Raya No.64, Jakarta, Indonesia \\ adm-sma@kanisius.edu
}

Diterima tanggal 15 Februari 2019

Disetujui tanggal 3 Desember 2019

\begin{abstract}
This paper discussed the history of thought of the natives in the Dutch East Indies in bringing forward their economy amidst the situation of colonialism. The educated modern middle class of bumiputra emerged as a result of the Dutch Ethical Policy. This group then influenced the mindset of bumiputra on viewing the modern economic situation. The thought of this educated modern class can be traced from two influential newspapers, such as Boedi Oetomo representing priayi and Soeara Moehammadijah representing santri. Using historical method, this paper showed that the economy of the Dutch East Indies was projected from the ideal view of the colonial government on a liberal economic system. Both newspapers provided different opinions in dealing with the situation, according to the cultural basis of the society they represented. Boedi Oetomo prioritized the modernization of the means of production, economic education, and improvement of business governance, whereas Soeara Moehammadijah showed that the way to improve the people's economy was based on community contributions and moral education.
\end{abstract}

Keywords: newspapers, Budi Utomo, Muhammadiyah, and economicmodernization.

\begin{abstract}
ABSTRAK
Tulisan ini membahas tentang sejarah pemikiran masyarakat bumiputra di Hindia Belanda dalam memajukan kondisi perekonomian mereka di tengah-tengah situasi kolonialisme. Politik Etis melahirkan kelas menengah modern yang terdidik dari masyarakat bumiputra. Kelompok ini kemudian memengaruhi pola pemikiran masyarakat bumiputra secara umum dalam memandang situasi ekonomi modern. Pemikiran kelompok kelas modern terdidik ini dapat ditelusuri dari dua surat kabar yang berpengaruh, seperti Boedi Oetomo yang mewakili kelompok masyarakat priayi
\end{abstract}


(tradisional dan modern) dan Soeara Moehammadijah yang mewakili kaum santri. Dengan menggunakan metode sejarah, tulisan ini menunjukkan bahwa perekonomian pada masa Hindia Belanda dibangun atas pandangan ideal pemerintah kolonial atas sistem ekonomi liberal. Kedua surat kabar memberikan opini yang berbeda dalam menghadapi situasi zaman modern, sesuai dengan basis kultural masyarakat yang diwakilinya. Boedi Oetomo mengutamakan modernisasi alat-alat produksi, pendidikan ekonomi, dan perbaikan tata kelola usaha, sedangkan Soeara Moehammadijah menunjukkan bahwa cara memperbaiki perekonomian masyarakat adalah berbasis sumbangan komunitas dan pendidikan moral.

Kata kunci: surat kabar, Budi Utomo, Muhammadiyah, dan modernisasi ekonomi.

\section{A. PENDAHULUAN}

Pada abad ke-20 terjadi perubahan pengelolaan ekonomi Hindia Belanda, dari pengelolaan negara ke pengelolaan swasta. Menguatnya suara kaum liberal di parlemen Belanda menuntut diterapkannya liberalisasi di tanah jajahan melalui disahkannya UndangUndang Agraria 1870 (van Zanden, 2012: 147) dan perluasan daerah koloni di luar pulau Jawa pada akhir abad ke19 (Linblad, 1989: 7-15). Kondisi ini mendorong berkembangnya pola ekonomi kapitalistik di Hindia Belanda.
Perkembangan ekonomi kapita listik ini semakin berkembang pascaPerang Dunia I. Investasi asing dalam bidang perkebunan mulai banyak bermunculan pada masa kepemimpinan Gubernur Jendral D. Fock (1921-1926) (Burger, 1970: 142-143). Kondisi ini tidak dapat dilepaskan dari tugas Fock yang harus memperbaiki kondisi keuangan Hindia Belanda dan Belanda pasca-Perang Dunia I (Ingleson, 1988: 296). Kehadiran investasi asing di Hindia Belanda dapat dilihat dalam tabel di bawah ini:

\begin{tabular}{|c|c|c|c|c|c|c|}
\hline \multirow{2}{*}{ Asal Negara } & \multicolumn{3}{|c|}{ Daerah Perkebunan } & \multirow{2}{*}{ Total yang } \\
\cline { 3 - 4 } & Jawa & $\begin{array}{c}\text { Sumatera } \\
\text { Timur }\end{array}$ & $\begin{array}{c}\text { Sumatera } \\
\text { Selatan }\end{array}$ & & \multicolumn{2}{c|}{$\begin{array}{c}\text { Total } \\
\text { diinvestasikan pada }\end{array}$} \\
\cline { 2 - 4 } & & 360,7 & 57,2 & 1535,9 & 779,6 & 756,3 \\
Belanda & 1118,0 & 124,7 & 11,2 & 277,9 & 10,1 & 297,8 \\
Inggris & 142,0 & 124,7 & Tanaman \\
Prancis-Belgia & 35,9 & 72,5 & 3,2 & 11,6 & - & 111,6 \\
Amerika & - & 53,0 & - & 53,0 & - & 53,0 \\
Jepang & 5,9 & 13,7 & - & 19,6 & 3,7 & 15,9 \\
Jerman & 5,7 & 8,1 & 4,0 & 17,8 & - & 17,8 \\
Swiss & - & 4,4 & 0,7 & 5,1 & - & 5,1 \\
Italia & 2,1 & - & - & 2,1 & - & 2,1 \\
Lainnya & 22,3 & 4,9 & 13,8 & 41,0 & - & 11,9 \\
\hline Total & 1332,4 & 642,2 & 90,4 & 2065,0 & 793,5 & 1271,5 \\
\hline Persentase dari & 16,1 & 44,1 & 36,8 & 25,7 & 1,7 & 40,5 \\
modal asing & & & & & & \\
\hline
\end{tabular}

Tabel 1. Jumlah modal perkebunan asing yang ditanam pada tiga daerah perkebunan di Hindia Belanda (dalam juta Gulden).

Sumber: Furnival, 1967: 311. 
Kemunculan perkebunan swasta ini menyebabkan Hindia Belanda menjadi pemasok utama kebutuhan bahan mentah dunia, seperti kina (93\%), kapuk (79\%), lada (70\%), karet (35\%), dan kopra (30\%) dari kebutuhan dunia pada pertengahan periode 1920 -an (Caldwell, 2011: 96).

Ekonomi kapitalistik memengaruhi masyarakat bumiputra yang masih berpola ekonomi subsisten. Ekonomi jenis ini muncul akibat hubungan kekerabatan dan penyaluran tenaga kerja dalam rangka menekan biaya operasional. Pertanian masyarakat bumiputra yang menggunakan pola ekonomi subsisten melibatkan partisipasi masyarakat dari awal penanaman hingga panen. Hasil panen dibagi sebagai pengganti tenaga yang dikeluarkan.

Kehadiran ekonomi kapitalistik di Hindia Belanda memicu modernisasi dalam bidang ekonomi moneter (Boeke, 1953: 108-109), perkebunan yang berorientasi ekspor (Boeke, 1953: 118-127), teknologi pertanian ala Barat (Goss, 2009: 187-192), industri pengolahan (Lindblad, 2002: 87-90), dan melahirkan beragam lapangan kerja (Angelino, 1931: 233-239).

Pola ekonomi subsisten mengalami perubahan akibat masuknya ekonomi kapitalistik. Kehadiran perkebunan swasta dan pabrik pengolahannya mengubah pola hidup masyarakat bumiputra. Perkebunan swasta seringkali mempergunakan lahan pertanian subur milik masyarakat.
Penjelasan lebih lanjut tentang berkembangnya dua model ekonomi di tanah Hindia (kapitalistik Eropa dan subsisten bumiputra) dapat dijelaskan dari teori dualisme ekonomi yang diperkenalkan oleh Boeke. Dirinya melihat bagaimana di dalam kehidupan ekonomi masyarakat Hindia Belanda terdapat tumpang tindih antara sistem kapitalistik Eropa yang pro akan modal dan gencarnya industrialisasi di segala bidang dengan sistem ekonomi secukup-hidup yang diorganisasikan secara komunal (subsisten) oleh masyarakat bumiputra (Brookfield, 1975: 54-55). Jalannya dua sistem ini membuat lahirnya keinginan dari masyarakat kelas menengah bumiputra yang telah mendapatkan pendidikan tinggi untuk membantu masyarakatnya agar ikut berpartisipasi dalam kondisi ekonomi yang unik ini.

Konsep spesialisasi kerja diperkenalkan melalui proses pengolahan bahan baku. Pabrik menyewa tenaga kerja dari penduduk sekitar dan mengupah mereka dengan uang. Perkebunan swasta mengambil lahan perkebunan bumiputra. Hal ini membuat lahan masyarakat semakin mengecil sehingga membuat mereka menggeluti pekerjaan di luar bidang pertanian. Kondisi tersebut membuat penggunaan uang semakin meningkat (Geertz, 1983: 89-109).

Ekonomi kapitalistik mulai memengaruhi pola hidup masyarakat bumiputra di Hindia Belanda, seperti munculnya arus urbanisasi ke pusat industri, pusat pemerintahan, maupun 
Handep Jurnal Sejarah dan Budaya

Vol. 3, No. 1, Desember 2019, hlm. 33-54

daerah pelabuhan (Booth, 2007: 114), terbentuknya kelas menengah (van Niel, 1984: 142), hingga muncul perubahan dalam struktur masyarakat bumiputra (Kartodirdjo, 1990: 80-92).

Upaya masyarakat bumiputra untuk ambil bagian dalam pola hidup kapitalistik erat kaitannya dengan pandangan hidup modern yang mulai muncul di awal abad ke-20 dan ditiru dari masyarakat Eropa yang tinggal di Hindia Belanda.

Dalam Modernity and Cultural Citizenship in the Netherlands Indies: An Illustrated Hypothesis, Nordholt (2011: 440) menyatakan bahwa modernisme yang diperkenalkan kolonialisme menjembatani tumbuhnya hasrat konsumtif melalui kemunculan iklan-iklan menarik berbagai barang massal yang dibuat di pabrik. Dari sinilah gaya hidup konsumtif di kalangan masyarakat bumiputra, terlebih dari golongan "priayi baru" yang menjadi kelas menengah masyarakat bumiputra mulai lahir dan berkembang.

Meskipun terjadi pertumbuhan investasi asing di Hindia Belanda, kesejahteraan masyarakat bumiputra masih berada di bawah masyarakat Eropa. Kondisi ini disebabkan oleh dua hal. Pertama, pemilik perkebunan swasta di Hindia Belanda adalah orang asing. Oleh karena itu, keuntungan akan mengalir ke luar negeri. Kedua, keuntungan dari meningkatnya harga komoditas tanaman ekspor tidak dinikmati petani bumiputra karena mereka hanya menanam tanaman pangan (Dick, 2002: 142-143).

Kondisi tersebut memperlihatkan kesenjangan antara ekonomi kapitalistik dengan ekonomi subsisten. Persaingan tersebut ikut menjadi perhatian organisasi pergerakan masyarakat bumiputra seperti Budi Utomo dan Muhammadiyah. Muncul berbagai macam pendapat dan wacana mengenai cara yang tepat dalam memperbaiki kondisi ekonomi masyarakat bumiputra melalui surat kabar dari masing-masing organisasi, yaitu Boedi Oetomo dan Soeara Moehammadijah. Kedua surat kabar tersebut memiliki basis massa tersendiri karena merupakan surat kabar bentukan organisasi induknya.

Budi Utomo dan Muhammadiyah merupakan organisasi yang memanfaatkan surat kabar sebagai media penyampai kritik atas kondisi perekonomian di Hindia Belanda dan mengajak pembaca menyikapi ekonomi kapitalistik yang berkembang di Hindia Belanda.

Melalui masing-masing surat kabarnya, kedua organisasi ini memiliki gaya yang berbeda dalam menjawab tantangan ekonomi yang dihadapi masyarakat bumiputra pada masa itu (Nordholt, 2011: 440). Melalui penelitian inilah penulis berusaha mengetahui bagaimana Boedi Oetomo dan Soeara Moehammadijah dalam membangun wacana pemikiran ekonomi yang ideal bagi masyarakat bumiputra dan melihat perbedaan pandangan dari kedua surat kabar tersebut dalam menanggapi per- 
masalahan ekonomi yang dihadapi.

Pembahasan tentang hubungan antara surat kabar dengan situasi ekonomi modern di Hindia Belanda pada awal abad ke-20 pernah dikaji oleh Riyanto dalam Iklan Surat Kabar dan Perubahan Masyarakat di Jawa Masa Kolonial (1870-1915). Karya ini membahas pembentukan identitas modern faktor konsumsi masyarakat bumiputra dengan kemunculan iklan surat kabar di masa kolonial. Kolonialisme di Nusantara membawa modernisasi ala Barat melalui pendidikan dan penetrasi ekonomi.

Meskipun Riyanto memberikan pemahaman baru dalam melihat konteks sosial ekonomi masyarakat Jawa dalam menghadapi gempuran ekonomi dan gaya hidup kapitalistik pada awal abad ke-20, karya tersebut hanya membahas aspek modernisasi dari pola konsumsi dan menitikberatkan pembahasannya dalam aspek visual dari iklan tersebut. Tanggapan masyarakat bumiputra sendiri dalam menghadapi modernisme ekonomi tidak disinggung sama sekali (Riyanto, 2000: 180-185)

Tujuan dari penelitian ini adalah untuk mengetahui pandangan ideal dari organisasi Budi Utomo dan Muhammadiyah dalam menerjemahkan konsep modernitas yang berkembang pada masa itu dan upaya kedua organisasi tersebut dalam membangun kondisi ekonomi masyarakat bumiputra.

Dari latar belakang yang sudah disebutkan di atas, penulis hendak mengetahui bagaimana kesenjangan ekonomi yang harus dihadapi oleh masyarakat bumiputra di tengah arus modernisasi ekonomi di Hindia Belanda pada awal abad ke-20 melalui pandangan kedua surat kabar ini.

Boedi Oetomo dan Soeara Moehammadijah menginginkan perbaikan kondisi ekonomi masyarakat bumiputra melalui beberapa cara, antara lain partisipasi mereka dalam kegiatan ekonomi kapitalistik dan perbaikan sistem pendidikan ekonomi dalam meghadapi pengaruh ekonomi kapitalistik yang berpusat pada penggunaan dan pemanfaatan modal secara efisien.

\section{B. METODE}

Dalam melakukan penelitian ini, penulis memakai metode penelitian sejarah yang terdiri atas empat tahapan, yaitu heuristik, verifikasi, interpretasi, dan historiografi (Kuntowijoyo, 1995: 89).

Tahap pertama, heuristik, dilakukan dengan mengumpulkan sumber-sumber sejarah baik berupa sumber primer (surat kabar) dan sumber sekunder (buku dan jurnal ilmiah). Sumber-sumber tersebut diperoleh dari Arsip Nasional Republik Indonesia, Perpustakaan Nasional, Perpustakaan Kolese St. Ignatius Kota Baru, Yogyakarta, Perpustakaan Universitas Sanata Dharma, dan Perpustakaan Universitas Gadjah Mada.

Tahap kedua adalah verifikasi. Dalam proses ini, penulis melakukan penyeleksian data dengan ketat lewat 
Handep Jurnal Sejarah dan Budaya Vol. 3, No. 1, Desember 2019, hlm. 33-54

penyesuaian antara topik penelitian dengan sumber-sumber yang berhasil dikumpulkan. Untuk sumber utama, penulis melakukan seleksi terhadap artikel-artikel yang terdapat di kedua surat kabar yang dipilih berdasarkan topik utama penelitian ini, yaitu tentang modernisasi ekonomi yang dilakukan masyarakat bumiputra. Adapun sumber pendukung seperti data-data statistik didapatkan dari berbagai macam buku dan jurnal penelitian yang membahas situasi dan kondisi zaman pada masa itu.

Tahap ketiga adalah interpretasi. Setelah melakukan penyeleksian artikel surat kabar, dilakukan upaya penelitian lebih lanjut guna mengetahui korelasi antara sumber sejarah dengan konteks peristiwa sejarah pada masa lampau dan bagaimana perkembangan pemikiran masyarakat di masa itu.

Tahap keempat adalah historiografi. Pada tahapan ini, dilakukan penulisan karya sejarah seperti yang tertuang di dalam jurnal ilmiah ini.

Penelitian ini sendiri merupakan pengembangan ide dari tesis penulis yang berjudul "Sejarah Pemikiran Modern Surat Kabar Boedi Oetomo dan Soeara Moehammadijah di Yogyakarta Tahun 1920-1928”. Ide modernisasi dalam kedua surat kabar tersebut dikerucutkan ke dalam pembahasan ekonomi masyarakat bumiputra pada konteks tahun 1920-an di Yogyakarta.

\section{HASIL DAN BAHASAN}

\section{Wacana Modernisasi Ekonomi Dalam Surat Kabar Boedi Oetomo Tentang Perbaikan Pola Ekonomi Masyarakat Bumiputra}

Perhatian Boedi Oetomo terhadap kondisi ekonomi pertanian sesuai dengan kebijakan organisasinya dalam memperbaiki kehidupan masyarakat bumiputra (van Miert, 2003: 426-427). Program ini berjalan berdampingan dengan program utama Budi Utomo di bidang pendidikan dan pelestarian kebudayaan Jawa. Budi Utomo melihat para petani bumiputra di Hindia Belanda harus melakukan perubahan dalam berbagai bidang, mulai dari memperbaharui pendidikan pertanian, cara pengelolaan tanah dan hasil panen, perlunya memilih bibit tanaman yang menguntungkan.

Metode perbaikan kesejahteraan yang diterapkan Budi Utomo merujuk pada upaya perbaikan kesejahteraan masyarakat bumiputra yang dilakukan pemerintah kolonial. Pemerintah kolonial berusaha membangun semangat wirausaha masyarakat bumiputra dalam bidang pertanian melalui Politik Etis, pendirian bank kredit dan pegadaian, serta mendirikan sekolah pertanian (Dirkse dan Husken, 1993: 230).

Budi Utomo menyadari bahwa kehadiran kolonialisme di Hindia Belanda mengubah tatanan yang sudah ada. Kondisi ini menjadi perbincangan yang serius dalam Budi Utomo, seperti dalam artikel yang berjudul "Lezingnja landbouwleeraar Oemarsanoesie 
dalam congres Boedi-Oetomo".

Artikel yang melaporkan suasana kongres Budi Utomo pada 1923 ini memberitakan pendapat Oemar Sanoesi, guru pertanian asal Yogyakarta, yang diundang untuk membahas tentang pentingnya keikutsertaan petani bumiputra dalam kegiatan perekonomian dunia. Oemar Sanoesi berpendapat bahwa perlunya pengetahuan baru bagi petani bumiputra agar dapat bertahan dalam perubahan zaman, yaitu tenaga kerja, modal, tanah, dan pengetahuan.

Melalui modernisasi sektor pertanian dapat dihasilkan keuntungan bagi pertanian masyarakat bumiputra, seperti yang diungkapkan dalam sepuluh usul modernisasinya di bawah ini:

1) Mempoenjai tabeat: menghitoeng sent.

2) Pandai, ertinja mengerti bagaimana djalannja menghitoeng berat ringannja peroesahaan jang sepadan dengan oentoengnja kelak. Dari itoe moesti tahoe aksara.

3) Dari bisa membatja, mengetahoei dan mentjoba pengetahoean asing jang berfaedah bagi pertaniannja.

4) Mengetahoei akalnja bekerdja bersama-sama (cooperatie).

5) Mendjoeal bersama-sama soepaja dapat harga pantes.

6) Pandai mendjalankan landbouwtechniek.

7) Dapat memilih benih, mengganti warna taneman menoeroet kehendak tanahnja.

8) Tjerdas memilih moesim menaboer benih, bertanem, d.s.b.

9) Mengetahoei daja oepaja boewat memlihara boewah tanamannja, soepaja dapat arga banjak.

10) Apabila kekoerangan ongkos, mengetahoei dan mendapat pindjaman oewang jang moerah (landbouwerediet).

(Boedi Oetomo, 4 Juni 1923: 1)

Konsep pertanian yang diperkenalkan Oemar Sanoesi menghasilkan industrialisasi pertanian yang bermuara pada keuntungan dan efisiensi. Hal ini menjadi bagian dari upaya mengadopsi pola pertanian modern yang diberikan dalam sekolah pertanian Hindia Belanda pada masa Politik Etis (Angelino, 1931: 240-243).

Oemar Sanoesi melirik ketidakmampuan perusahaan perkebunan swasta dalam memenuhi kebutuhan akan produk pertanian yang dibutuhkan dunia saat itu (Mansvelt, 1975: 22). Kondisi tersebut sudah dipraktikkannya dengan mengajak para petani bumiputra di kawasan Magelang dan Turi untuk menanam kelapa dan terbukti mampu meningkatkan kesejahteraan petani di daerah tersebut (Boedi Oetomo, 4 Juni 1923: 1).

Hal tersebut dapat dilihat dalam tabel pertumbuhan volume ekspor dan kemampuan pemenuhan petani kecil bmiputra dalam membantu memasok barang kebutuhan tersebut: 
Handep Jurnal Sejarah dan Budaya Vol. 3, No. 1, Desember 2019, hlm. 33-54

\begin{tabular}{|c|c|c|c|c|c|}
\hline \multirow[t]{2}{*}{ Tahun } & \multicolumn{2}{|c|}{ Semua Produk Ekspor } & \multicolumn{2}{|c|}{ Produksi Petani Kecil } & \multirow{2}{*}{$\begin{array}{c}\text { Produksi Petani Kecil } \\
\text { Sebagai Presentase } \\
\text { Jumlah Seluruhnya }\end{array}$} \\
\hline & Indeks & Pertumbuhan & Indeks & Pertumbuhan & \\
\hline 1893 & 40,8 & - & 28,7 & - & 12,2 \\
\hline 1898 & 50,3 & 4,3 & 34,4 & 3,7 & 11,8 \\
\hline 1903 & 64,9 & 5,2 & 50,0 & 7,8 & 13,4 \\
\hline 1908 & 79,3 & 4,1 & 77,9 & 9,2 & 17,0 \\
\hline 1913 & 100,0 & 4,7 & 100,0 & 5,1 & 17,3 \\
\hline 1918 & 118,9 & 3,5 & 118,2 & 3,4 & 17,2 \\
\hline 1923 & 155,1 & 5,5 & 217,6 & 13,0 & 24,3 \\
\hline 1928 & 226,0 & 7,8 & 35,8 & 10,4 & 27,3 \\
\hline 1933 & 213,3 & $-1,1$ & 399,3 & 2,3 & 32,4 \\
\hline 1938 & 239,9 & 2,4 & 518,5 & 5,4 & 37,4 \\
\hline 1893-1928 & \multirow{2}{*}{-} & 5,0 & \multirow{2}{*}{ - } & 7,5 & \multirow{2}{*}{ - } \\
\hline $1893-1938$ & & 4,0 & & 6,6 & \\
\hline
\end{tabular}

Tabel 2. Pertumbuhan volume ekspor 1893-1938. Sumber: Booth, 2007: 376-377.

Pentingnya keikutsertaan kaum bumiputra dalam perekonomian dunia juga dibahas dalam artikel yang berjudul "Regeering dan Staatsbedrijf". Dalam artikel ini, penulis melaporkan pembicaraan di dalam rapat Volksraad, antara perwakilan tuan Salim, Stokvis, dan Dahler yang mengeluarkan mosi keberatan akan jalannya usaha yang dilakukan oleh staatsbedrijf (perusahaan pemerintah) terhadap daerah Hindia Belanda. Keberatan ini muncul dikarenakan oleh tiga hal, yaitu:

1) voor het voeren van een juiste van den Indischen Archipel,

2) ter, beperking van de uitstrooming van winsten van het particuliere koloniale kapitaal,

3) voor een deugdelijk financieel en maatschappelijk landsbeheer,
1) melakukan yang terbaik bagi Kepulauan Hindia,

2) melakukan pembatasan atas penghabisan keuntungan modal dari pihak swasta kolonial,

3) melakukan pengelolaan terhadap lahan keuangan dari pihak masyarakat umum.

(Boedi Oetomo, 15 Januari 1925: 1)

Pandangan tersebut didasarkan akan perlunya usaha perekonomian yang dilakukan oleh masyarakat bumiputra melalui Particuliere Exploitatie (Eksploitasi Swasta). Melalui Particuliere Exploitatie yang dijalankan oleh masyarakat bumiputra hasil bumi dan hasil usaha yang berasal dari tanah Hindia Belanda dapat dijaga dan tidak lari ke negeri induk. 
Dalam artikel tersebut dijelaskan bahwa selama dipegang oleh staatsexploitatie (eksploitasi negara), banyak sekali pendapatan dari hasil bumi dan hasil usaha yang berasal dari tanah Hindia lari ke negeri Belanda. Akibatnya, masyarakat bumiputra hanya menjadi penonton dan buruh di negeri sendiri. Masyarakat bumiputralah pembayar pajak yang terbesar. Pada 1919 , masyarakat bumiputra membayar $44 \%$ dari adanya semua pajak dan $50 \%$ dari "pametoenja kaboedidajan negeri" (Boedi Oetomo, 1925: 1).

Boedi Oetomo menjadi sarana penyalur wacana kondisi perekonomian ideal yang dicita-citakan oleh Budi Utomo. Melalui artikel-artikelnya, surat kabar tersebut menekankan wacana pentingnya pendidikan ekonomi bagi masyarakat bumiputra dan perlunya mengikuti perkembangan zaman. Beberapa diantaranya adalah mencintai barang produksi sendiri, membangun semangat kewirausahaan, memperbaiki semangat bersaing secara sehat, dan kemauan untuk bekerja sama dengan orang di luar kelompoknya.

Hubungan antara politik dan ekonomi sendiri dipandang oleh Boedi Oetomo sebagai sumber kekuatan bagi kemandirian masyarakat bumiputra. Dalam pembahasan yang ada di dua artikel, yaitu "Politiek dan Economie haroes bertoekaran kekoewatan" dan "Politiek dan Economie".

Dalam artikel yang pertama, Budi Utomo menyadari bahwa kekuatan ekonomi dan politik harus berjalan bersama guna memberi posisi tawar bagi masyarakat bumiputra. Melalui artikel ini, Soetopo menyampaikan perlunya kerja sama antara masyarakat bumiputra dengan masyarakat lain, seperti masyarakat Tionghoa Peranakan (Boedi Oetomo, 13 Agustus 1923: 1; Claver, 2014: 138-144; dan Astuti, 2008: 1).

Dalam artikel tersebut, penulis melihat pentingnya usaha untuk menggabungkan perjuangan kaum bumiputra dengan kaum Tionghoa peranakan guna mencapai tujuan hidup sejati. Hal ini dilihat oleh Soetopo dalam perumpamaan kerja sama antara Rama dan Sugriwa (Boedi Oetomo, 29 Juni 1923: 1)

Pentingnya politik dan ekonomi dalam mewujudkan masyarakat bumiputra dan Tionghoa yang hidup terbebas dari tekanan bangsa lain juga diungkapkan dalam artikel kedua yang ditulis Anoman. Anoman menganalogikan perjuangan masyarakat bumiputra seperti medan perang antara prajurit (kaum pergerakan) melawan pihak kolonial.

Lemahnya prajurit bumiputra dikarenakan tidak ada yang mengurusi bagian dapur (ekonomi) yang memberi makan. Adapum pihak lawan (gouvernment) disokong oleh berbagai macam departemen (binnenlandschbestuur, landbouw, dll.). Karenanya, tidak heran bila banyak aksi protes masyarakat bumiputra selalu gagal (Indonesia, 1981: 62-63) dan pemerintah Hindia mendapat pembenaran untuk memperkuat sektor pertahanan (Boedi Oetomo, 22 Januari 1923). 
Anoman melihat bahwa rusaknya dunia pergerakan bumiputra disebabkan oleh diri bumiputra sendiri yang tidak mau rukun dengan sesamanya dan bekerja keras demi kebaikan bersama. Seperti yang diucapkan oleh Anoman dalam kalimatnya di dalam artikel tersebut:

“Djikalau orangjang ta' tertoetoep mata hati boedi (boeta mata batin) misti tida taoet menanggoeng soesah dan pajah serta bekerdja berat boeat mengedjar kebaikan oemoem, malahan mengerti bahwa manoesia dititahkan di'alam doenia misti haroes kerdja berat goena tangga naik soearga. Dari itoe, dipadalangan ada sindiran "Soeargo ginawe hajoe". Memang sesoenggoehnja orang akan selamat diachirat itoe, haroes berdjalan selamat di'alam doenia.

Dimana-mana negeri djika pendoedoeknja koerang jang bertabi'at satrija misti tiada ada ketertiban oemoem, jang tjotjok dengan pengharapan Ra'jat, karena boesoek dan kebaikan negeri itoe tertarik dari keloeroesan hati orang. Djadi bahasa oerang koeno: "Besoek zaman achir boemi moendak tjioeté," ketjoeali tambahnja djiwa orang jang membikin koerangnja hatsil tanah, dari koerangnja orang Djawa jang berwatek satrija menimboelkan djoega koerang berkatnja hatsil tanah bagi keperloean 'oemoem. Misalnja: orang seroemah tangga ada 5 orang mempoenjai nasi satoe bakoel ketjil, kalau sikepala roemah bisa kenjang makan sesoeap nasi sahadja, misti orang seisi roemah peroetnja berisi nasi; akan tetapi apabila sikepala roemah besar peroet dan biasanja kalau makan memakai adjang pandjang (Jv) gambar Grameh jang besar, soedah misti disitoe ada orang jang tida mendapat bagian nasi sesoeap poen." (Boedi Oetomo, 28 Desember 1923: 1)

Dalam artikel ini, disebutkan bagaimana keberadaan Sugriwa dan Rama sebagai representasi dari bangsa bumiputra dan Tionghoa peranakan, sedangkan Eropa dan Jepang digambarkan sebagai Subali dan Dasamuka. Hubungan Sugriwa dan Rama menjadi representasi antara hubungan bangsa Tionghoa dengan bumiputra, seperti tampak dalam tulisan penulis di bawah ini:

"Negri Tjina baroe kaloet, tanah Djawa dalem djaman riboet, bangsa Tionghwa masih takoet dari sebab dididiknja tabeat menoeroet, sedang bangsa kita merreboet nama djadi pemoeka jang kesohornja tjoema tinggal di alam Seboet. Meskipoen Tàotjang dan ketinggian dan perbeda'an telah diboewang, panglingnja kaoem politiek dan kaoem economie menoeroet perasa'an Timoer masih sadja terpiara, oleh karena Economie jang beralasan pikiran Barat hingga pada waktoe ini masih terpandang sebagai badji Pontjo Soono.

Setelah Praboe Romo berdjoempah dengan Soegriwo baharoelah kera Poetih aken keliatan tenaganja. Tabeat anak Giri Nata ini terlampau merendahkan diri dan takoet memboeka rahasia Doenia. Akan tetapi apabila Romo soedah 
maoe memrintah, Hanomanlah

jang djadi Oetoesannja" (Boedi

Oetomo, 28 Desember 1923: 1).

Melalui analogi cerita wayang Ramayana, dikisahkan penyatuan tenaga antara Sugriwa dan Rama menjadi jalan bagi datangnya Hanoman yang membantu Rama mendapatkan kembali Sri Sinta dari tangan Dasamuka. Melalui analogi tersebut, penulis meminta agar kaum Tionghoa dan bumiputra dapat bekerja sama demi terwujudnya kekuatan untuk melawan Subali dan Dasamuka (Eropa dan Jepang) yang pada saat artikel tersebut ditulis sedang membuat keresahan di dalam dunia.

Perjuangan di bidang ekonomi didorong untuk membangun perusahaan yang dikelola oleh kaum bumiputra sendiri. Hal ini penting agar masyarakat bumiputra tidak menjadi penonton di negeri sendiri saat perusahaan asing datang dan menanamkan modalnya. Kemampuan masyarakat bumiputra dalam membangun perusahaan tidak dapat dianggap sepele oleh masyarakat Belanda maupun Tionghoa totok pada masa kolonial, meskipun baru terpusat pada jumlah dan kelompok industri tertentu (Budiman dan Onghokham, 2016: 105).

Keberadaan usulan dari surat kabar Boedi Oetomo mengenai perbaikan ekonomi dalam masyarakat bumiputra menjadi sebuah penanda dari upaya membangun basis ekonomi berdasarkan perbaikan pola manajemen, pendidikan ekonomi, dan kepekaan dalam membangun aliansi dagang baik dengan sesama masyarakat Jawa maupun dengan suku bangsa lain seperti Tionghoa (Claver, 2014: 138144). Hal ini memberikan informasi bahwa modernisasi ekonomi yang diusung oleh organisasi Budi Utomo melalui surat kabarnya adalah upaya keterbukaan akan ide-ide baru dan membuka cakrawala dengan perkembangan dunia luar yang dinamis (Prabowo, 2018: 170-174).

\section{Wacana Modernisasi Ekonomi} Dalam Surat kabar Soeara Moehammadijah Tentang Perbaikan Gaya Hidup Masyarakat Bumiputra

Soeara Moehammadijah membahas degenerasi moral masyarakat bumiputra akibat kemunculan ekonomi kapitalistik Barat. Hal tersebut terlihat dari munculnya upaya memodernisasikan diri pada kelas menengah bumiputra agar sama seperti masyarakat Barat.

Kondisi tersebut dibuktikan dari munculnya iklan-iklan kebutuhan tersier seperti tempat berlibur, perabot listrik rumah tangga, jam tangan, jas, rokok, makanan-makanan Barat, jasa kereta api, dan minuman keras di surat kabar Hindia Belanda sejak awal abad ke 20 (Riyanto, 2000: 180-185). Keinginan memiliki barang-barang modern sebagai upaya meniru modernitas masyarakat Barat menjadi cara bagi masyarakat baru kelas menengah bumiputra dalam menjadi bagian dari kultur masyarakat Kolonial (Ingleson, 2011: 439-440). 
Kritik terhadap sikap konsumtif yang lahir dalam masyarakat bumiputra dibahas dalam Soeara Moehammadijah dalam artikel bersambung yang berjudul "Zaman Concurentie". Artikel tersebut membahas dua bagian yang berbeda di mana artikel pertama membahas kegilaan masyarakat dalam mencari barang-barang palsu (emas palsu, berlian palsu, bahkan arloji palsu) buatan Inggris, Jerman, Italia, Perancis, dan Amerika guna menaikkan derajat mereka di mata orang lain (Soeara Moehammadijah, November 1923: 216).

Dalam artikel kelanjutannya penulis membandingkan kondisi dari orang-orang yang membeli barangbarang palsu tadi dengan mereka yang berusaha sekuat tenaga mencari surga. Melalui analoginya, penulis mengibaratkan surga sebagai sebuah barang yang "mahal" dan tidak "dijual" di sembarang tempat. Untuk mendapatkannya seseorang harus "membelinya" dengan susah payah, dan tidak semua orang mampu "membayar" harganya (Soeara Moehammadijah, November 1923: 216).

Surga dikatakan "mahal" karena menggunakan "uang" yang asli, yaitu amal dan doa di dunia serta menjalankan peraturan dalam agama Islam. Sementara, "sulit didapat" karena dalam Islam jika seseorang berdosa, dirinya harus bertobat kepada Tuhan langsung, bukan kepada Nabi Muhammad sebagai utusan Tuhan di dunia. Sulitnya menuju surga diungkapkan oleh penulis seperti di dalam kutipan artikel di bawah ini:

"Barang siapa hendak membeli soerga dalam agama Islam, haroeslah lebih dahoeloe berdjandji dengan oetjapan dan jang teroes didalam hati sanoebarinja:

a. Menjaksikan dengan oetjapan teroes dihati, bahwa tiadalah Toehan jang wadjib disembah, melainkan Toehan Allah.

b. Menjaksikan dengan oetjapan, teroesan hati bahwa Djoendjoengan $K . \quad N$. Moehammad itoe pesoeroeh Toehan Allah.

c. Berdjandji soeka dengan ichlas hatinja, bahwa ia sanggoep mendjalankan Sembahjang lima waktoe, sehari semalamnja.

d. Berdjandji soeka dengan ichlas hatinja, bahwa saban setahoen sekali, kalau mempoenjai harta, benda dagangan, jang seharga f 50,- akan memberikan 2 1/2\% dari harta itoe. Dan kalau mempoenjai Mas dan Perak menoeroet timbangan jang telah tjoekoep, sanggoep memberikan sebagian samestinja, kepada Fakir Meskin dan lain-lain orang jang mempoenjai hak (sebagai Zakat).

e. Berdjandji sanggoep didalam setahoen seboelan dalam boelan Ramelan poeasa, menoeroet Sjarat dan roekoennja.

f. Berdjandji sanggoep, bahwa bilamana selama hidoep didoenia ada koeasa dari hal sangoe pergi dan poelangnja, dan koeasa akan badannja; dan aman pada djalannja, sekali pergi ketanah Soetji perloe 
mengerdjakan kaperloean Hadji.

g. Berdjandji sanggoep Soennat (potong koelit kemaloean bagi lelaki dan perempoean, menoeroet peratoeran agama Islam) seoemoer hidoep sekali.

h. Berdjandji sanggoep berboeat kebadjikan manakala berkoeasa menoeroet sjarat dan roekoennja.

i. Berdjandji sanggoep menjelebarkan engatahoean agama Islam kepada anak saudaranja dan sekalian menoesia jang koerang mengarti tentang itoe, dengan menoeroet perintah dan firman Toehan dan sabda Djoendjoengan $K . \quad N$. Moehammad s.a.w.

j. Berdjandji sanggoep mendjaoehi segala larangan Toehan dan Rasoelnja.

Demikian ringkesnja perdjandjian Agama Islam, oentoek membeli Soerga didalam agama Islam." (Soeara Moehammadijah, November 1923: 216)

Kutipan artikel di atas menjelaskan pembaca bahwa jalan untuk selamat di dunia yang penuh dengan ekonomi kapitalistik dan perilaku hidup konsumtif adalah dengan menjalani dan mengamalkan kembali ajaran agama Islam. Hal tersebut dilaksanakan dengan menjalankan ajaran agama Islam (Shadily, 1984: 2956), seperti rukun Islam (poin a sampai f), menjalani sunat (poin g), mengamalkan kebajikan (poin h), menyebarkan ajaran agama Islam (poin i), dan menjauhi larangan Tuhan dan para rasulnya (poin $\mathrm{j}$ ).
Soeara Moehammadijah mengingatkan kepada pembaca dan kaum Muslim bumiputra bahwa kehadiran harta benda di dunia adalah titipan dari Allah dan hendaknya dipergunakan secara sebaik-baiknya. Cara yang bijak untuk mencegah konsumerisme adalah dengan melaksanakan kewajiban sosial agama Islam, yaitu zakat (Tripp, 2006: 56).

Melalui zakat, Soeara Moehammadijah mengingatkan pembaca untuk membantu saudara-saudara mereka yang hidup dalam kekurangan dan menjalankan kembali tradisi kaum Muslimin. Kondisi ini tidak terpisahkan dari pemahaman kaum intelektual Muslim terhadap kondisi zaman yang dipengaruhi pola hidup konsumtif dan menyusutkan proses religi masyarakat Muslim (Tripp, 2006: 52).

Soeara Moehammadijah mendorong masyarakat Muslim di Hindia Belanda untuk ikut berperan dalam kegiatan perekonomian guna menolong sesama saudara kaum Muslim yang mengalami nasib yang kurang beruntung. Kehadiran ekonomi dimaknai oleh Muhammadiyah sebagai kendaraan menuju kemandirian masyarakat. Peran serta dari ekonomi ini menjadi bagian dari proses ekonomi moral yang digalakkan oleh organisasi Muhammadiyah.

Beberapa contoh artikel yang membahas tentang perlunya kaum Muslim di Hindia Belanda untuk memperoleh kemandirian dalam bidang ekonomi adalah "Sedikit waktoe mahal djoega harganja", "Bengat 
oemat Islam!", dan "Benda Doenia".

Dalam artikel yang ditulis Sadija dengan judul "Sedikit waktoe mahal djoega harganja", dijelaskan akan pentingnya menghargai waktu meski hanya sejam saja. Waktu dipahami sebagai penentu kehidupan manusia karena darinya masyarakat dapat hidup sejahtera atau tidak. Penjelasan penulis dapat dilihat di dalam artikel tersebut seperti di dalam kutipan artikel di bawah ini:

"Inilah harganja waktoe dan pahalanja radjin dalam doenia. Dan lagi dalam chadis telah mentjeritakan Tjaharilah harta benda sebagai kamoe akan hidoep kekal, dan tjaharilah achirat seperti kamoe akan mati besoek pagi.

Chadis ini menjoeroeh, soepaja kami haroes radjin mentjari harta benda, bila kami memikirkan akan hidoep selama-lamanja dan djoega menjoeroeh soepaja kami haroes radjin mentjari acherat, bila kami memikirkan akan mati besoek pagi. Djadi soedah terang sekali bahwa kami haroes radjin mentjari doenia dan achirat bersama- sama. Lagi poela dalam Al Koeranoel Aziez djoega ada firman jang maksoednja soepaja kami haroes radjin (djangan menjia-njiakan waktoe)." (Soeara Moehammadijah, November 1923: 213)

Penggunaan analogi jual beli barang dipakai dalam menjelaskan hubungan diri manusia terhadap agama Islam, seperti dalam artikel yang berjudul "Bengat oemat Islam!". Penulis mengistilahkan situasi yang dialami para pemeluknya seperti kondisi jual beli dalam kegiatan perdagangan, yaitu bengat (yang dalam bahasa Arab artinya dijual). Adapun maksud dari penulis adalah seperti di bawah ini:

"Manoesia memeloek agama Islam artinja memperbengatkan badannja, fikirannja, hartabendanja kehadapan Toehan, djoega berarti masoek sekoetoe tentara Islam. Orang Islam sengadja menetapi le. kalimah sahadad doea jang demikian boenjinja: Ashadoe'alla ilaha il'lalloh. Wa.

Ashadoe anna Moechamadarasoeloeloh.

Adapoen artinja Tiada lain lagi Toehanjang Alah sendiri tilah jang berhak dimoeliakan jang haroes kita sembah, tetapi hanjalah Toehan dan kita pertjaja sebenarnja K. N. Moehammad itoe oetoesan Toehan.

2e. Sesoedah pertjaja dengan sempoernanja hati, oentoek Toehan dan K. N. Moehammad s.a.w. maka seharoesnja meninggikan, mendjoendjoeng dan memoeliakan agama Islam; menetapi kebenaran menghilangkan segala kesalahan dan kedjahatan. orang Islam berani membela kesetiannja pada agamanja, dengan mengorbankan badan djiwanja oentoek sabihilah sebagai firman Toehan dalam Al Qoer'an demikian." (Soeara Moehammadijah, 1925: 1).

Kedua artikel di atas memperlihatkan upaya Soeara Moehammadijah dalam menjelaskan kepada pembaca bahwa bekerja merupakan bagian dari 
ibadah untuk menolong sesamanya yang kesulitan. Kehadiran kerja keras di dunia menjadi tanda dari upaya manusia untuk sungguh-sungguh mendalami ajaran agama Islam, termasuk usaha mengikuti perkembangan zaman dan berpartisipasi dalam roda ekonomi modern. Pesan tersebut semakin ditegaskan dalam artikel yang berjudul "Benda Doenia".

Artikel ini berupaya menyadarkan pembaca bahwa meskipun bukan sebagai alat identitas kelas dan pembentuk kekayaan, harta duniawi berperan penting dalam memajukan kehidupan sesama kaum Muslim. Menurut penulis, bila kaum Muslim di Hindia tidak bekerja keras mencari harta duniawi, maka tidak akan mungkin mampu membangun sekolahsekolah yang dapat mengangkat derajat hidup kaum Muslim di Hindia Belanda.

Penulis menguatkan pembaca bahwa kaum Muslim harus ikut serta dalam usaha mencari harta dunia, seperti yang diteguhkan dalam kutipan artikel di bawah ini:

"Karena sesoenggoehnja Toehan Alah mendjadikan Doeni seisinja itoe oentoek segala manoesia bangsa a a sadja, ta' perdoeli Moe'min atau kafir, barang siapa menoetoet, dapatlah ia. Malahan kita orang Islam itoe mestinja haroes lebih pandai dari orang kafir tentang pentjaharian doenia itoe, karena didalam ajat Qur'an jang moelia ada bebrapa ratoes ajat jang memrintahkan kita orang Islam mentjahari harta benda, baik benda jang di dalam laoet mauepoen jang didalam goenoeng2 Apakah Qur'an memerintahkan demikian itoe, kita boleh meninggalkan? Djika meninggalkan nistjajalah kita teroes meneroes karendahannja lebih dari pada masa sekarang ini. Dari pada itoe kami membangoenkan saudara2 kita. Toentoetlah segala pengatahoean jang menghasilkan doenia, djangan soeka males meningalkan pentjaharian terseboet!" (Soeara Moehammadijah, Moeharam 1345: 313-317).

Karena kewajiban sosial yang dimiliki oleh kaum Muslim bersifat beragam, perlulah kaum Muslim bumiputra untuk menguasai sektor ekonomi agar dapat membangun berbagai sarana dan prasarana yang dapat membantu sesama kaum Muslim. Seperti Muhammadiyah yang mencontohkannya melalui pembangunan sekolah, rumah yatim piatu, rumah sakit, dan rumah miskin. Seperti yang diungkapkan di bawah ini:

"Djika kita orang Islam ini tida berharta. Apakah kita dapat beli tanah jang tjoekoep oentoek mendirikan romah sekolah d.l.l. jang mendjadi hadjat kita akan menjempoernakan hidoep kita bersama? Tentoe tida.

Kalau kita orang Islam tida mempoenjai sekolahan sendiri, dapatkah sempoerna kepandean kita? Dan apakah kiranja bangsa kita Islam jang dapat sengsara dapat pertolongan? Darimanakah dan siapakah jang soeka menolong? Sedang kita sendiri ta' memperdoelikan Apakah lain golongan soeka mentjoekoepi 
keperloean hidoep kita. Inilah toean pembatja dapat menimbang sendiri. Dari itoe kami berseroe sekali lagi. Marilah saudara sama memadjoekan anak-anak kita kepada sekolahan jang dapat menjampaikan kaperloean terseboet, maskipoen anak kita itoe sampai berapa tahoen oemoernja. Djika anak anak kita tida kami perhatikan pengatahoeanja, apakah dapat mentjahari harta benda? En apakah kita orang jang soeda toea toea ini bisa bersekolah sebagei anakanak? Tentoe tida." (Soeara Moehammadijah, Moeharam 1345: 313-317)

D a 1 a $\mathrm{m}$ p e $m$ a ha m a n Muhammadiyah, kerja keras merupakan bagian dari ibadah. Melalui kerja keras diperoleh penghasilan yang dapat dipergunakan untuk membangun fasilitas sosial atau membuka lapangan kerja baru bagi sesama manusia yang membutuhkan. Penjelasan tersebut memperlihatkan bahwa agama menjadi motivasi bagi manusia untuk menjalankan roda perekonomian yang baik disertai tanggung jawab moralnya (Haryono, 2011: 44). Kondisi ini sama seperti yang dihadapi oleh berbagai kaum puritan di seluruh dunia yang memandang kerja keras sebagai bagian dari ibadah (Weber, 1965: 158-178).

Soeara Moehammadijah mengingatkan ajaran dalam agama Islam tentang tindakan nyata dalam kewajiban moral dan sosial. Seperti pelayanan sosial dalam bentuk kesehatan, pendidikan dan merawat masyarakat miskin (Nakamura, 1983:
102-112). Dengan menjalankan ajaran dalam Al-quran dan Hadist (Kesin, 2011: 29) dan mengadopsi nilai-nilai modernitas, Muhammadiyah mengisi posisi strategis kaum muslim bumiputra sambil menopang keadilan sosial dan kemakmuran ekonomi mereka (Kesin, 2011: 38).

Zakat menjadi salah satu sumber pemasukkan dalam membiayai kegiatan operasional Muhammadiyah. Di cabang Yogyakarta, zakat menjadi sumber pemasukan kedua terbesar setelah subsidi dari Pemerintah Kolonial dan Keraton Yogyakarta. Pada 1923 , pendapatan dari zakat mencapai 23.962 Gulden (37\% pendapatan Muhammadiyah cabang Yogyakarta) dan pendapatan dari pemerintah kolonial dan Keraton Yogyakarta masing-masing mencapai 6.461 Gulden dan 1.500 Gulden. (Zanden dan Luiten, 2014: 6-12). Kebanyakan mereka yang menyumbangkan zakat berasal dari golongan kelas menengah bumiputra seperti kaum pedagang Muslim (van Zanden, 2014: 6; Gwenaël, 2014: 6-12).

Upaya melaksanakan tanggung jawab moral tersebut menjadi cara menghadapi gelombang kapitalisme yang melanda Hindia Belanda. Muhammadiyah sadar upaya melawan kapitalisme asing tidak hanya dilakukan dengan mengadaptasi usaha di bidang ekonomi saja, tetapi juga melalui tanggung jawab sosial kaum Muslim bumiputra dalam membangun komunitasnya. Muhammadiyah terbuka dengan ide-ide modernisasi dalam kehidupan sehari-hari dan meng- 
adopsinya tanpa meninggalkan identitas keislamannya (Alfian, 1989: 150).

Dari kumpulan artikel tersebut dapat terlihat bahwa organisasi Muhammadiyah sudah memiliki pemikiran untuk meningkatkan taraf hidup masyarakat Muslim melalui perekonomian. Meskipun memiliki tujuan yang sama seperti organisasi Budi Utomo, organisasi Muhammadiyah lebih menekankan pada pembangunan komunitas dari dalam tanpa melibatkan masyarakat di luar komunitasnya.

Kondisi ini tercermin di dalam surat kabar organisasinya, Soeara Moehammadijah menekankan pembangunan taraf hidup kaum Muslim berada di tangan masyarakat Muslim itu sendiri. Pembangunan berbasis komunitas dengan menyisihkan penghasilan dapat dipakai untuk membangun fasilitas sosial seperti sekolah dan rumah sakit yang nantinya akan berguna bagi kemaslahatan umat.

\section{SIMPULAN}

Melalui penelitian ini dapat diketahui bahwa perekonomian pada masa Hindia Belanda dibangun atas pandangan ideal pemerintah kolonial akan sistem ekonomi liberal, yang memberikan posisi bagi pihak swasta dalam menanamkan investasinya di Hindia Belanda. Untuk mencapai hal tersebut, Pemerintah kolonial menjalankan kebijakan Politik Etis yang tidak hanya meningkatkan kesejahteraan masyarakat bumiputra tetapi juga menjadi landasan infrastruktur bagi pertumbuhan investasi swasta.

Hadirnya model ekonomi kapitalistik di Hindia Belanda mulai menggeser pola perekonomian subsisten yang dikenal masyarakat bumiputra. Muncul pengaruh baru seperti lahirnya kelas menengah bumiputra, munculnya hasrat untuk ikut aktif dalam kehidupan ekonomi modern, serta lahirnya sikap konsumtif.

Boedi Oetomo dan Soeara Moehammadijah menyoroti kondisi tersebut serta memberikan alternatif guna mempersiapkan masyarakat bumiputra dalam menghadapi perubahan zaman. Wacana akan kondisi ekonomi ideal dan cara yang harus ditempuh dipengaruhi oleh basis kultural yang dimiliki oleh organisasi induknya.

Boedi Oetomo memberi penjelasan bahwa perubahan zaman tidak dapat dihindari oleh masyarakat bumiputra. Masyarakat bumiputra harus beradaptasi dengan kondisi tersebut dengan menerima metode kerja modern, menambah pengetahuan ekonomi, serta berani bekerja sama dengan pihak-pihak yang ada di luar golongannya guna mencapai kepentingan bersama.

Boedi Oetomo mengajak para pembaca untuk berani membuat keputusan dalam tingkatan individu. Keberanian adalah batu pijakan bagi munculnya kemandirian ekonomi masyarakat bumiputra di dunia. 
Soeara Moehammadijah memusatkan perhatiannya pada penegakan ajaran agama Islam sebagai cara memutus jerat rantai kapitalisme dan konsumerisme. Dengan menegakkan ajaran agama Islam, tidak hanya keselamatan dunia saja yang akan didapatkan, tetapi juga keselamatan di surga. Jalan menujunya adalah dengan melaksanakan kewajiban umat Islam dalam membantu sesamanya melalui zakat.

Soeara Moehammadijah selalu menekankan aspek sosial, yang terlihat dari pentingnya pembangunan dalam masyarakat Muslim. Kondisi ini dapat dicapai melalui kesadaran masyarakat Muslim untuk rajin bekerja dan menyisihkan penghasilannya demi pembangunan kesejahteraan umat. Soeara Moehammadijah memperkenalkan nilai pembangunan dan pemberdayaan komunitas dengan partisipasi individu.

Tentu saja kedua surat kabar tersebut tidak dapat dipisahkan dari basis kultural organisasi induk yang menaunginya, yaitu Budi Utomo dan Muhammadiyah. Kedua organisasi tersebut memiliki caranya masingmasing dalam menyampaikan pemikiran mereka.

Konsep modernisasi ekonomi di dalam perkembangan sejarah ekonomi Indonesia menjadi bagian dalam perjalanan sejarah yang tidak dapat dipisahkan dari kondisi zaman yang menyertainya. Kolonialisme Belanda di Hindia Belanda membawa berbagai pengaruh modern yang mau tidak mau harus dihadapi oleh masyarakat Bumiputra.

Kedua organisasi dari masyarakat bumiputra di Yogyakarta memberikan berbagai macam cara dalam membangun kemandirian ekonomi masyarakat bumiputra. Meskipun keduanya sama-sama menjadi organisasi bercorak modern, pola yang dipakai sangat berbeda satu dengan lainnya.

Budi Utomo menekankan pendidikan tentang ekonomi dan bagaimana ekonomi dapat memengaruhi segala bentuk pergerakan masyarakat bumiputra, terlebih bagi pergerakan politik. Adapun organisasi Muhammadiyah menekankan keseimbangan antara, kegiatan perekonomian masyarakat dengan kewajiban ber-sedekah kaum Muslim bagi para saudara-saudaranya yang masih belum sejahtera.

Dari pola tersebut dapat diketahui bahwa organisasi Budi Utomo, melalui surat kabarnya mengajak masyarakat untuk terbuka dan sadar bahwa perubahan harus dilakukan dengan menerima pengaruh dari luar tanpa melupakan jati diri yang dimiliki. Adapun Muhammadiyah melalui surat kabarnya memiliki kecen-derungan untuk bersikap defensif terhadap perubahan yang berasal dari luar dan berusaha membangun struktur yang kuat di dalam dengan berkaca dari pengalaman di luar dan mengadaptasinya sesuai dengan kebutuhan mereka. 
Simpulan yang dapat diambil dari penelitian ini adalah upaya kedua surat kabar di atas yang berusaha memperkenalkan konsep otonomi diri dalam hal ekonomi. Surat kabar Boedi Oetomo dan Soeara Moehammadijah melihat perlunya masyarakat bumiputra untuk mengenal modernisme bukan pada tangkapan luarnya saja, melainkan pada tataran ilmu pengetahuan dan sikap hidup.

Setiap individu memiliki peran yang menentukan kesejahteraan atas dirinya dan komunitas masyarakatnya. Maju atau mundurnya kondisi tersebut didasarkan oleh keputusan dan tindakan dari masing-masing individu. Selain itu, pijakan kemandirian melalui kearifan dalam menggunakan sistem perekonomian modern dan keawasan dalam memahami perubahan menjadi wacana utama yang hendak disebarkan kedua surat kabat tersebut kepada pembaca.

Berkaca dari kondisi yang dihadapi oleh masyarakat Indonesia sekarang dengan pada masa lampau tidaklah jauh berbeda. Oleh sebab itu, penulis memberi saran bahwa penting bagi masyarakat Indonesia untuk mengadaptasi perkembangan perekonomian modern sesuai dengan konteks masyarakat yang ada. Dengan cara ini, kemampuan untuk beradaptasi dengan sistem ekonomi modern dapat dilakukan tanpa harus kehilangan jati diri dan kebudayaan yang sudah ada.

\section{E. REKOMENDASI}

Melalui penelitian ini, diharapkan para sejarawan dapat menggunakan surat kabar tidak hanya sebagai sumber pelengkap dalam penelitian saja, melainkan juga sebagai sumber utama dalam mengetahui pemikiranpemikiran dalam masyarakat yang berkembang pada masa itu.

\section{F. UCAPAN TERIMA KASIH}

Penulis berterima kasih kepada SMA Kanisius Jakarta tempat kerja penulis atas kesempatan bagi penulis untuk mengembangkan diri. Lewat berbagai bimbingan, kritik, serta saran karya tulis ini dapat penulis selesaikan.

Penulis tidak lupa mengucapkan banyak terima kasih kepada Jurnal Handep yang telah memberikan kesempatan bagi penulis untuk mengirimkan karya ilmiah.

\section{DAFTAR SUMBER}

Alfian. 1989. Muhammadiyah, The Political Behavior of a Muslim Modernist Organization Under Dutch Colonialism. Yogyakarta: Gadjah Mada University Press.

Angelino, A.D.A. De Kat. 1931. Colonial Policy. The Hague: Martinus Nijhoff.

Astuti, Meta Sekar Puji. 2008. Apakah Mereka Mata-Mata? Orang-Orang Jepang di Indonesia (1868-1942). Yogyakarta: Ombak.

Boedi Oetomo. 1923. Soetopo, Baart Strijd, maar geeft Voldoening. 3 

Vol. 3, No. 1, Desember 2019, hlm. 33-54

Januari.

Boedi Oetomo. 1923. BEZUINIGING ONDERWIJS DAN GEZONDHEIDSDIENST. 22 Januari, hlm. 1.

Boedi Oetomo. 1923. Soetopo, Politiek dan Economie haroes bertoekaran kekoewatan. 29 Juni, hlm. 1

Boedi Oetomo. 1923. Tionghoa peranakan bergerak. 13 Agustus, hlm. 1.

Boedi Oetomo. 1923. B. Politiek dan economie. 28 Desember, hlm. 1.

Boedi Oetomo. 1925. Regeering dan Staatsbedrijf. 15 Januari, hlm. 1.

Boedi Oetomo. 1925. Lezingnja landbouwleeraar Oemarsanoesie. 4 Juni, hlm. 1.

Boedi Oetomo. 1925. Economie kita. 25 November

Boeke. J. H. 1953. Economics and Economic Policy of Dual Societies as Exemplified by Indonesia, Haarlem: H.D. Tjeenk Willink \& Zoon N.V.

Booth, Anne E. 2007. Colonial Legacies, Economic, and Social Development in East and Southeast Asia. Honolulu: University of Hawai'i Press.

Brookfield, Harold. 1975. Interdependent Development, Perspectives on Development. U.S.A: University of Pittsburgh Press.
Budiman, Amen \& Onghokham. 2016. Hikayat Kretek. Jakarta: Kepustakaan Populer Gramedia.

Burger, D. H. 1970. Sedjarah Ekonomis Sosiologis Indonesia, Djilid Kedua. Jakarta: Pradnja Paramita.

Caldwell, Malcolm. 2011. Sejarah Alternatif Indonesia. Yogyakarta: Penerbit Djaman Baroe.

Claver, Alexander. 2014. Dutch Commerce and Chinese Merchants in Java. Leiden: Brill.

Dick, Howard. 2002. The Emergence of a National Economy. Honolulu: University of Hawai'i Press.

Dirkse, Jan-Paul dan Frans Husken. 1993. Development and social welfare: Indonesia's experiences under the new order. Leiden: KITLV Press.

Furnival, J.S. 1967. Netherlands India, a Study of Plural Economy. London: Cambridge University Press.

Geertz, Cliford. 1983. Involusi Pertanian, Proses Perubahan Ekologi di Indonesia. Jakarta: Bhratara Karya Aksara.

Goss, Andrew. 2009. Decent Colonialism? Pure Science and Colonial Ideology in the Netherlands East Indies, 1910-1929. Journal of Southeast Asian Studies 40 (1), hlm. 187-192. 
Gwenaël Njoto-Feillard. 2014.

Financing Muhammadiyah: The

Early Economic Endeavours of a Muslim Modernist Mass Organization in Indonesia (1920s-1960s). Studia Islamika 21 (1), hlm. 6-12.

Haryono, Anton. 2011. Sejarah (Sosial) Ekonomi, Teori Metodologi Penelitian dan Narasi Kehidupan. Yogyakarta: Penerbit USD.

Ingleson, John. 1981. Bound Hand and Foot: Railway Worker and the 1923 Strike in Java, Indonesia 31, hlm. 439-440.

. 1988. Urban Java during the Depresion. Journal of Southeast Asian Studies 19 (2), hlm. 296.

Kartodirdjo, Sartono. 1990. Pengantar Sejarah Indonesia Baru: Sejarah Pergerakan Nasional, dari Kolonialisme Sampai Nasionalisme Jilid 2. Jakarta: PT. Gramedia.

Kuntowijoyo. 1995. Pengantar Ilmu Sejarah. Yogyakarta: Bentang.

Kesin, Tugrul. 2011. The Sociology of Islam, Secularism, Economy and Politics. Reading: ITHACA PRESS.

Lindblad, J. Thomas. 1989. Economic Aspect of the Dutch Expansion in Indonesia 1870-1914. Modern Asian Studies, 23 (1), hlm. 7-15. . 2002. Fondasi Historis

Ekonomi Indonesia. Yogyakarta:
Pustaka Pelajar.

Mansvelt, W.M.F. 1975. Changing Economy in Indonesia, a Selection of Statistical Source Material from the early 19th Century up to 1940. The Hague: Martinus Nijhoff.

Nakamura, Mitsuo. 1983. Bulan Sabit Muncul dari Balik Pohon Beringin, Studi Tentang Pergerakan Muhammadiyah di Kotagede, Yogyakarta. Yogyakarta: Gadjah Mada University Press.

Nordholt, Henk Schulte. 2011. Modernity and Cultural Citizenship in the Netherlands Indies: an Illustrated Hypothesis. Journal of Southeast Asian Studies 42, hlm. 440.

Prabowo, Rechardus Deaz. Sejarah Pemikiran Modern Surat Kabar Boedi Oetomo dan Soeara Moehammadijah di Yogyakarta Tahun 1920-1928. Tesis. Yogyakarta: Universitas Gadjahmada.

Riyanto, Bedjo. 2000. Iklan Surat Kabar dan Perubahan Masyarakat di Jawa Masa Kolonial (18701915). Yogyakarta: Tarawang.

Shadily, Hasan, et al. 1984. Ensiklopedi Indonesia $5 P-S H F$. Jakarta: Ichiar Baru-Van Hoeve.

Soeara Moehammadijah. 1923. Sadija, Sedikit waktoe mahal djoega harganja. November, hlm. 213. 
Soeara Moehammadijah. 1923. H.F., Zaman concurentie. November, hlm. 216.

Soeara Moehammadijah. 1925. Bengat oemat Islam!, hlm. 1.

Soeara Moehammadijah. 1345. H.A. Aziz, "Benda Doenia". edisi Moeharam, hlm. 313-317.

Tripp, Charles. 2006. Islam and the Moral Economy, The Challenge of Capitalism. New York: Cambridge University Press.

Van Miert, Hans. 2003. Dengan Semangat Berkobar, Nasionalisme dan Gerakan Pemuda di Indonesia, 1918-1930. Jakarta: Hasta Mitra.

Van Niel, Robert. 1984. Munculnya Elite Modern Indonesia. Jakarta: Pustaka Jaya.

Van Zanden, Jan Luiten. 2012. Ekonomi Indonesia 1800-2010, Antara Drama dan Keajaiban Pertumbuhan. Jakarta: Penerbit Buku Kompas.

Weber, Max. 1965. The Protestant Ethic and the Spirit of Capitalism. London: Unwin University Books. 